\title{
TUHAN MENURUT TUHAN: Narasi Ilahiyah dalam Hadis Qudsī
}

\author{
Miswari \\ Program Studi Pendidikan Agama Islam Fakultas Tarbiyah dan Ilmu Keguruan IAIN Langsa \\ Jl. Meurandeh, Langsa, 24411, Aceh, Indonesia \\ Email: miswari@iainlangsa.ac.id
}

\begin{abstract}
This article aims to develop a narrative about God and the things associated with Him by using some sources of hadith Qudsi. When we mention one hadith Qudsi, it requires a lengthy exposition statement, even though the message in a hadith very brief. For general reader who has no capability in analyzing hadith, it is not make a sense for them. This paper discuss about how to take the core message in a hadith Qudsi on divinity and things related on it. Hadith Qudsi become an option for the author since discourses on religion and divinity generally rarely refer to the hadith Qudsi. The author want discribe the comparison between the image of God about Himself in the hadith Qudsi and in the Quran and Hadith. God in the hadith Qudsi seemed very close, very merciful and far from the negative image such as grumpy and punishment. The relationship between God and human in the hadith Qudsi seems more lovely and peaceful since God's love to His creature.
\end{abstract}

Kata Kunci: God, Hadith Qudsī, Human, Heaven

\begin{abstract}
Abstrak
Artikel ini bertujuan menyusun narasi yang tentang Tuhan dan hal-hal yang berkaitan dengan-Nya dengan menggunakan sumber hadis qudsī. Seperti diketahui bahwa satu hadis saja, termasuk hadis $q u d s \bar{l}$, ketika disampaikan membutuhkan keterangan perawian yang panjang lebar. Sementara ini pesan dalam sebuah hadis sangat singkat saja. Hal ini kurang berguna bagi pembaca umum yang bukan bertugas menganalisa hadis. Untuk itu tulisan ini dibuat dengan mengambil inti pesan dalam hadis qudsī tentang ketuhanan dan hal-hal yang berkaitan. Hadis qudsī menjadi pilihan penulis karena umumnya referensi tentang agama dan ketuhanan jarang merujuk hadis qudsī. Pulis menunjukkan bahwa gambaran Tuhan tentang diri-Nya dalam hadis qudsī berbeda dengan gambaran yang umumnya ditemukan di dalam Alquran dan Hadis. Tuhan dalam hadis qudsī tampak sangat dekat, sangat pemurah dan jauh dari citra negatif seperti pemarah dan pengazab. Hubungan Tuhan dengan manusia dalam hadis qudsī lebih identik dengan hubungan cinta kekasih.
\end{abstract}

Kata Kunci: Tuhan, Hadis Qudsī, Manusia, Surga

\section{Pendahuluan}

Alquran dan hadis adalah referensi utama dalam Islam. Hadis adalah perkataan, perbuatan dan sikap Nabi Muhammad atas perbuatan orang lain. Dari segi makna, hadis terbagi menjadi dua yaitu yang berasal dari Nabi Muhammad sendiri dan dari Allah. Hadis yang dari Allah itu disebut hadis qudsī. Hadis qudsì dan Alquran sama-sama berasal dari kalam
Allah. Namun perbedaan keduanya adalah, hadis qudsī tidak tertulis di Lawh Mahfūzz sebagaimana Alquran. Membaca Alquran menjadi ibadah, tetapi membaca hadis qudsī tidak. ${ }^{1}$

Mengenal Tuhan melalui Alquran dan hadis sudah sangat sering dilakukan. Tetapi mengenal Tuhan melalui hadis $q u d s \bar{\imath}$

${ }^{1}$ Achmad Sunarto \& Syamsuddin Noor, Himpunan Hadis Qudsī (Jakarta: An-Nur, 2005), 1. 
masih jarang dilakukan. Bahkan hadis qudsī sangat jarang digunakan dalam pengembangan keilmuan Islam. Tuhan melalui Alquran dan hadis lebih dikenal sebagai sosok yang dualis. Pada satu sisi dia adalah Maha Baik yang menjanjikan segala kebaikan bagi yang taat kepada-Nya. Tetapi pada sisi yang lain, Dia sekaligus adalah sosok yang bersedia memberi hukuman sekeras-kerasnya bagi siapapun yang berani menentang perintah-Nya.

Dalam hadis qudsī, Tuhan lebih dikenal sebagai satu wujud yang Mulia, Pemurah dan Pemaaf. Tidak ada personifikasi kejam dan pemarah pada Tuhan dalam hadis qudsī. Semua konotasinya positif. Umpamanya bagi pelaku dosa, bila dalam Alquran dan hadis umat dapat menjadi pesimis akibat dosadosa yang dilakukan, tetapi di dalam hadis $q u d s \bar{l}$, kasih sayang Tuhan disebutkan tidak terbatas. Dia bersedia mengampuni hambaNya sebanyak apapun dosa hamba tersebut. Untuk itulah, pesan-pesan hadis qudsī yang belum menjadi perhatian banyak pihak perlu dieksplorasi, khususnya tentang tema ketuhanan.

Tulisan ini berusaha membentuk sebuah narasi utuh tentang inti pesan dari seratus satu hadis qudsī tentang ketuhanan. Hadis-hadis ini dikumpulkan oleh Ibn
'Arabī, dan kerap diungkapkan dalam mengajarkan ajaran-ajarannya. Dengan membuat sebuah narasi utuh dari seratus satu hadis yang kerap digunakan seorang 'ārif diharapkan dapat membangun sebuah perspektif sederhana tentang bagaimana gambaran Tuhan menurut 'urafä'.

\section{Narasi Ketuhanan dalam Hadis Qudsī}

Allah mengharamkan kezaliman pada Diri-Nya dan kepada makhlukNya. Dia memperingatkan juga bahwa sekalian manusia adalah sesat. Maka manusia harus memohon petunjuk kepada-Nya. Sekalian manusia juga lapar. Maka manusia harus meminta makan kepada-Nya. Sekalian manusia telanjang, sehingga harus memohon pakaian kepada-Nya. Sekalian manusia berbuat salah siang dan malam sehingga harus selalu memohon ampunanNya. Manusia tidak mampu memberi mudarat sekaligus tidak mampu memberi manfaat. Segala sekalian manusia dari segala zaman dan pada sekalian alam, itu semua tidak menambah sesuatu apapun pada kerajaan-Nya. ${ }^{3}$

\footnotetext{
${ }^{2}$ Kumpulan 101 hadis qudsī yang dihimpun Ibn 'Arabi diberi judul Miskat Al-Anwar dan telah diterbitkan di Indonesia. Lihat, Ibn 'Arabi, Relung Cahaya: Seratus Satu Hadis Ketuhanan (Jakarta: Pustaka Firdaus, 1998).

${ }^{3}$ Iqbal pernah mengatakan bahwa Bayazid AlBistami pernah menukil sebuah hadis qudsī dengan mengatakan bahwa kondisi Allah adalah sama saja baik sebelum kejadian alam semesta maupun sekarang ini. Lihat, Muhammad Iqbal, Rekonstruksi
} 
Demikian juga sejahat-jahat apapun makhluk-makhluk, tidak mengurangi apapun dari Kerajaan-Nya. Sekiranya sekalian makhluk memohon kepada-Nya, maka itu tidak akan mengurangi apapun pada-Nya, hanya seperti jarum tercelup samudra saja. Tetapi semata-mata karena perbuatan sang makhluklah yang dihitung Allah semuanya untuk hamba-Nya. Karena itu, sesiapa mendapati yang baik, maka hendaknya dia memuji Allah. Tetapi bila tidak mendapati seperti itu, makhluk tidak diperkenankan mencela kecuali dirinya sendiri. ${ }^{4}$

\section{Demikian keagungan Allah} sehingga dari segala yang diper-sekutukan, hanya Dia yang tidak butuh pada yang dipersekutukannya. Siapa saja yang mempersekutukan Allah, maka Dia lepas tangan dan Dia milik yang dipersekutukannya. Sebaliknya orang yang disayang Allah adalah dia yang bagus akidahnya, kurang hartanya, menemukan nasibnya dalam sem-bahyang, banyak ibadatnya, taat pada-Nya baik sembunyi maupun terang, tidak popular, rezekinya pas-pasan namun sabar dengan semua itu. Maka orang demikian kematiannya akan dipercepat, tangisnya sedikit dan

Pemikiran Religius dalam Islam (Bandung: Mizan, 2016).

\footnotetext{
${ }^{4}$ Segala kebaikan adalah dari Allah dan segala keburukan adalah dari manusia. Yusep Rafiqi, Belajar Hidup Dari Allah (Jakarta: Gramedia, 2015), 41.
}

peninggalannya sangat kurang. Di antara yang lainnya yang dicintai Allah adalah orang yang suka memaafkan saudaranya.

Untuk menjadi hamba yang dicintai tidak mudah. Sebaliknya menjadi yang dibenci tidak susah. Segala keindahan surga semestinya sesiapa yang telah mendengar kabar tentangnya tidak ada yang tidak memasuki. Tetapi Allah menutupnya dengan segala perkara yang enggan dilakukan manusia sehingga jangan-jangan tidak ada yang memasukinya. Sebaliknya seharusnya sesiapa yang pernah mendengar kabar tentang betapa mengerikannya neraka tidak akan memasukinya. Tetapi Allah mensamarkan neraka dengan segala kenikmatan syahwat sehingga hampir semua memasukinya. Tetapi kuncinya juga sangat mudah. Misalnya hanya dengan mengucapkan basmalah, ${ }^{5}$ dan al-Fātihahah, maka Allah lupakan semua keburukannya dan Allah terima semua kebaikannya. Dia akan dijauhkan dari siksa neraka.

Tentunya yang harus dilakukan adalah membuat Allah senang, bukan sebaliknya membuat-Nya murka. Kemurkaan Allah terjadi ketika manusia mencerca Allah dengan mengatakan Dia memiliki anak dan mendustakan-Nya dengan mengatakan bahwa Dia tidak

${ }^{5}$ Tentang keagungan Basmalah, lihat Syaikh Abdil Qadir Jaelani, Bekal yang Cukup Menuju Allah Azza Wajalla (Jakarta: Sahara, 2009), 196197. 
mampu membangkitkan kembali manusia yang mana padahal penciptaan pertama lebih mudah bagi-Nya. Menyenangkan Allah juga adalah dengan mengingat-Nya yang berarti bersyukur pada-Nya. Pula membuat Allah marah adalah dengan melupakan Dia yang berarti mengingkariNya.

Dengan bersyukur kepada Allah, berarti manusia telah membangun hubungan yang tiada putus dengan-Nya. Bentuk syukur yang sekaligus membangun hubungan dengan Allah salah satunya adalah dengan berinfak. Barang siapa yang berinfak di jalan Allah, maka pula Allah berinfak kepada-Nya. Dan perlu disadari bahwa semenjak azali hingga kini dan akan datang, dengan keluasan alam, dari Allah tidak pernah kurang sedikitpun. Begitulah kekayaan dan keagungan-Nya. Bagai-mana kondisi bila hubungan dengan Allah telah terbangun? Ketika dia menyebut nama Allah, maka bibirnya berserak dengan-Nya.

Sekaligus hubungan itu dibangun dengan terus takut hanya kepada Allah. Karena barang siapa yang takut kepada Allah di dunia, maka dia aman di akhirat. Juga sebaliknya bila merasa aman terhadap Allah di dunia, maka dia tidak akan aman di akhirat.

Orang yang aman di akhirat adalah yang berada dalam naungan Allah. Mereka adalah orang yang selalu berbaik sangka kepada Allah. Dia sesuai dengan sangkaan hamba-Nya. Karena tidak ada apapun yang dirasakan hamba kecuali sesuai dengan sangkaannya kepada Tuhannya.

Umumnya manusia selalu membentuk sangkaannya kepada Allah selalu merujuk kepada apa-apa yang dimilikinya di dunia. Padahal, apapun yang paling berharga di dunia ditukar dengan azab yang paling ringan ketika manusia berada di neraka, dia tetap bersedia menukarnya. Sementara Allah sejak manusia dalam sulbi Adam, Allah telah meminta yang lebih ringan dari azab itu, yaitu sebuah usaha untuk menjauhkan diri dari neraka. Usaha itu harus dibarengi dengan tidak menentang kebesaran dan keagungan Allah. Setiap manusia dituntut untuk memburu keridaan Allah. Karena itu sanggup memasukkan ke dalam surga orang-orang yang tidak pernah melakukan satu kebaikanpun sehingga menjadiabu hitam di neraka.

Dengan keridaan Allah, maka segala kebaikan akan Dia limpahkan. Kenikmatan surga beserta segala isinya. Di atas itu ada juga sebuah anugerah yang paling besar dari Allah yang merupakan sebuah nikmat tertinggi yaitu kesempatan melihat wajah Allah. Tetapi anugerah itu hanya didapat oleh sangat sedikit orang. Orang-orang demikian adalah yang rela terhadap segala ketentuan Allah dan tidak meng- 
orientasikan agama untuk kepentingankepentingan duniawi. ${ }^{6}$ Kepada hambahamba yang salih, Allah telah mempersiapkan apa yang mata tidak pernah melihatnya dan apa yang telinga tidak pernah mendengarnya.

Karunia Allah tidak terbatas. Juga hasrat manusia. Oleh sebab itu, manusia harus selalu menghasratkan kepada kebaikan sehingga hasrat untuk itu terus bertambah sehingga dia masuk ke dalam surga Allah. Selayaknya hasrat untuk kebaikan itu terus-menerus diikuti dan terus-menerus ditambahkan. Karena manusia tidak tahu berapa umurnya.

Manusia harus beribadah dengan tulus, lepas dari segala orientasi selain Allah. Seperti bersedekah dengan tangan kanan yang mana tangan kiri tidak boleh mengetahuinya. Ketulusan ini harus beserta dengan pengenalan yang benar kepada Allah. Karena bila tidak, neraka menjadi tempat kembali. Pengenalan ini dilandasi dengan sangka yang baik kepada Allah.

Maka itu hendaklah manusia selalu berbaik sangka kepada Allah. Dia hamba berharap dan memohon hanya kepada Allah, maka Dia mengabulkan permohonan itu. Kalau dosa-dosa manusia seluas bumi, Allah tetap mengampuni kalau dia mau memohon ampun. Maka hendaklah

\footnotetext{
${ }^{6}$ Ahzami Samiun Jazuli, Kehidupan dalam Pandangan Alquran (Jakarta: Gema Inani Press, 2006), 376.
}

memurnikan ketaatan dan permohonan hanya kepada Allah. Manusia harus sadar bahwa segala sesuatu terjadi karena Allah, bukan akibat sesuatu lainnya. Misalnya, manusia harus meyakini bahwa hujan itu adalah berkat rezeki Allah dan rahmatnya. Barang siapa yang mengatakan sesuatu bukan dari Allah, maka dia kafir. Seperti mengatakan hujan turun itu karena bintang yang begini-begitu. ${ }^{7}$

Allah sangat membenci orang-orang yang melupakan-Nya. Padahal semua yang diterima manusia, bahkan wujudnya saja adalah dari Allah. Seharusnya manusia selalu mengucap syukur kepada Allah. Dia selalu mendengar pujian yang diucapkan hamba-Nya. Dia juga mengabulkan apa yang diminta hamba-Nya. Allah sangat senang ketika hamba-Nya memuji dan meminta kepada-Nya. Karena pada kenyataannya pujian hanya layak dialamatkan dan permintaan hanya layak dituju kepada Allah saja.

Selain itu, Allah mencintai seseorang dengan menganugerahkan keikhlasan ke dalam hatinya. Allah juga mencintai orang yang saling berkasih sayang demi keluhuran-Nya. Bila Allah

${ }^{7}$ Sebelum sains maju, hujan dikatakan dating dari Allah, tapi sekarang dikatakan karena matahari menarik air laut, air danau dan air pada baju basah di jemuran lalu mengumpulannya di langit hingga turun hujan. Kemajuan sains semakin membuat ingatan bahwa Allah sebagai penyebab segala kejadian terabaikan. 
mengambil sesuatu darinya, maka Allah membalasnya di surga. Sebaliknya kepada orang-orang yang menipu dunia dengan agama, yaitu orang yang kulit berbulu domba sementara hati serigala, mereka akan dikiramkan bencana hingga yang paling sabar di antara mereka bingung.

Rasulullah, Muhammad Saw sebagai adalah insan yang paling tinggi keikhlasannya, paling menyayangi ummatnya. Beliau bahkan sangat memikirkan nasib ummatnya di hari kiamat. Orang-orang yang mendapatkan syafaat darinya, maka diberikan kemudahan oleh Allah untuk masuk ke dalam surga. Untuk itu, hendaklah kita senantiasa memanjatkan salam dan bersalawat kepada beliau.

Maka hendaklah manusia mengaktualisasikan kecintaannya kepada Allah dan rasul-Nya. Barangsiapa yang banyak beribadah, maka Dia dadanya dipenuhi kekayaan dan dilimpahkan rezeki untuknya. Tetapi Bila tidak, maka Allah akan menyibukkan kita dan membendung rezeki. Hal ini sangat alamiah karena "tidak ada Tuhan selain Allah." Oleh sebab itu, siapa saja yang mengucap kalimat tauhid dengan tulus menjelang kematian, maka dia dijauhkan dari api neraka.

Manusia harus beribadah dengan tulus, lepas dari segala orientasi selain Allah. Seperti bersedekah dengan tangan kanan yang mana tangan kiri tidak boleh mengetahuinya. Ketulusan ini harus beserta dengan pengenalan yang benar kepada Allah. Karena bila tidak, neraka menjadi tempat kembali. Pengenalan ini dilandasi dengan sangka yang baik kepada Allah.

Maka itu hendaklah manusia selalu berbaik sangka kepada Allah. ${ }^{8}$ Dia hamba berharap dan memohon hanya kepada Allah, maka Dia mengabulkan permohonan itu. Kalau dosa-dosa manusia seluas bumi, Allah tetap mengampuni kalau dia mau memohon ampun. Maka hendaklah memurnikan ketaatan dan permohonan hanya kepada Allah. Manusia harus sadar bahwa segala sesuatu terjadi karena Allah, bukan akibat sesuatu lainnya. Misalnya, manusia harus meyakini bahwa hujan itu adalah berkat rezeki Allah dan rahmat-Nya. Barangsiapa yang mengatakan sesuatu bukan dari Allah, maka dia kafir. Seperti mengatakan hujan turun itu karena bintang yang begini-begitu.

Allah sangat membenci orang-orang yang melupakan-Nya. Padahal semua yang diterima manusia, bahkan wujudnya saja adalah dari Allah. Seharusnya manusia selalu mengucap syukur kepada Allah. Dia selalu mendengar pujian yang diucapkan hamba-Nya. Dia juga mengabulkan apa yang diminta hamba-Nya. Allah sangat

${ }^{8}$ Yunardi S \& Muhammad, Kekuatan Memaafkan (Jakarta: Qibla, 2014), 127. 
senang ketika hamba-Nya memuji dan meminta kepada-Nya. Karena pada kenyataannya pujian hanya layak dialamatkan dan permintaan hanya layak dituju kepada Allah saja.

Selain itu, Allah mencintai seseorang dengan menganugerahkan keikhlasan ke dalam hatinya. Allah juga mencintai orang yang saling berkasih sayang demi keluhuran-Nya. Bila Allah mengambil sesuatu darinya, maka Allah membalasnya di surga. Sebaliknya kepada orang-orang yang menipu dunia dengan agama, yaitu orang yang kulit berbulu domba sementara hati serigala, mereka akan dikiramkan bencana hingga yang paling sabar di antara mereka bingung.

Rasulullah, Muhammad Saw sebagai adalah insan yang paling sempurna, ${ }^{9}$ paling tinggi keikhlasan-Nya, paling menyayangi ummatnya, beliau bahkan sangat memikirkan nasib ummatnya di hari kiamat. Orang-orang yang mendapatkan syafaat darinya, maka diberikan kemudahan oleh Allah untuk masuk ke dalam surga. Untuk itu, hendaklah kita senantiasa memanjatkan salam dan bersalawat kepada beliau.

Maka hendaklah manusia mengaktualisasikan kecintaannya kepada Allah dan rasul-Nya. Barangsiapa yang

${ }^{9}$ Quito R. Motinggon, Keajaiban Cinta: Membuat Hidup Lebih Berenergi dan Dinamis (Jakarta: Hikmah, 2005), 64. banyak beribadah, maka dadanya dipenuhi kekayaan dan dilimpahkan rezeki untuknya. Tetapi bila tidak, maka Allah akan menyibukkan kita dan membendung rezeki. Hal ini sangat alamiah karena "tidak ada Tuhan selain Allah." Oleh sebab itu, siapa saja yang mengucap kalimat tauhid itu menjelang kematian, maka dia dijauhkan dari api neraka. Itulah jalan pesuluk.

Ibrahim mengeluh kepada Tuhannya, betapa takutnya dia bila Allah menjauhkan dirinya dari sisi-Nya. Padahal Adam dijadikan dengan tangan-Nya dan ditiupkan ruh-Nya. Itu terjadi karena pembangkangan kekasih kepada kekasinya sangat berat. Sebab itu pula Allah mengingatkan Daud agar memperingatkan Bani Israil dari syahwat. Karena itu membuat akal tertutup daripada Allah. Hal itu dapat terjadi kapanpun, sehingga Allah memerintahkan Musa agar selalu memperbanyak zikir kepada-Nya. Dengan itu Allah dapat menjadi teman duduk, Dia menjadi senantiasa dekat.

Setiap pecinta tentunya ingin bersatu dengan kekasihnya. Setiap pecinta harus benar-benar mengenali kekasihnya. Sebab itulah setiap insan yang mencintai Allah harus menyibukkan diri denganNya. ${ }^{10}$ Allah menjanjikan kebun surga kepada mereka. Kekasih Allah tentu

${ }^{10}$ Iman harus dibarengi amal, amal harus bermodalkan ilmu. Lihat, Abdul Qadir Isa, Hakekat Tasawuf (Jakarta: Qisthi Press, 2005), 65. 
mengingat-Nya dalam kondisi apapun termasuk dalam perang. Sebaliknya yang menentang Allah, seperti mendahului-Nya dengan bunuh diri, maka kepada mereka diharamkan surga. Sebab itu manusia harus selalu sadar bahwa tempat kembali hanya kepada Allah. Sehingga kehidupan di dunia yang hanya sesaat seyogyanya hanya dipergunakan untuk beribadah kepada Allah. Bila tidak, maka di hari kiamat, yang dituai hanya kedukaan dan penderitaan.

Bila manusia rela terhadap apa yang diberikan Allah, maka Dia akan membuat hati dan badan hamba-Nya gembira, serta sang hamba menjadi orang yang terpuji. Tetapi bila tidak rela terhadap pemberian Allah, maka dia akan dibuat seperti hewan liar di gurun, menjadi terhina. Maka itu ketaatan hanya patut kepada Allah saja. Karena hanya Allah saja yang menghendaki kebaikan untuk diri manusia itu sendiri. Sementara yang lain menghendaki hanya untuk kepentingan dan keuntungan dirinya semata. Selayaknya manusia tidak mengorientasikan dirinya untuk dunia. Sebab walau bagaimanapun, senikmatnikmat kenikmatan yang dialami di dunia, tidak ada apa-apanya dibandingkan secuil kenikmatan surga. Demikian juga sepahit dan sepedih apapun penderitaan hidup di dunia, maka tidak ada apa-apanya dibandingkan secuil kesengsaraan di neraka.
Allah amat berkuasa menguasai nasih setiap hamba. Menjadikan menusia dari debu lalu setetes sperma saja sangat mudah bagi-Nya. Mudah juga bagi-Nya melimpahkan segala kenikmatan di akhirat kelak bagi hamba-hamba yang taat. Itu semua adalah anugerah dari hak Allah mencintai hamba. Maka selayaknya juga manusia mencinta kepada Allah. Allah menjadikan manusia dengan kebesarannya, dipilihkan-Nya kepada manusia dari NamaNya yang indah. Dialah Raja. Maka siapa yang berdoa, dikabulkan-Nya, siapa yang memohon adan dianugerahi dan siapa yang memohon ampun, akan diampuni.

Benar-benar Allah Maha Mulia. Bila hamba berniat akan melakukan kebaikan, maka dicatat-Nya satu. Bila hamba melakukannya, maka dicatat sepuluh. Bila berniat melakukan keburukan, tidak dicatat-Nya. Bila melakukan keburukan itu, hanya dicatat sesuai yang dilakukan.

Karena keluhuran-Nya, Allah jadikan manusia, lalu Dia menjadikan sesuatu karena manusia. Sebab itu, tidak layak manusia menghancurkan apa-apa yang Dia ciptakan untuk mereka itu. Manusia juga juga tidak patut untuk bersikap gegabah seperti menuntut untuk rezeki esok karena Dia tidak menuntut manusia untuk pekerjaan esok. Segala sesuatu ada waktunya, maka Allah hanya 
menuntut sesuatu sesuai waktunya, misalnya menganjurkan salat empat rakaat di permulaan siang agar Allah mencukupkan kebutuhan manusia hingga akhirnya. Dengan kecukupan yang diberikan Allah, maka hendaklah manusia bersedekah sesegera mungkin. Karena bila ajal telah di kerongkongan, itu tidak mungkin lagi dilakukan. Sehingga hendaklah manusia menyegerakan diri untuk kebaikan sebagaimana Allah menyegerakan nikmat bagi manusia segera setelah kapasitasnya tersiapkan.

Dengan segala kebaikan yang diberikan Allah, maka hendaklah manusia menyusulkan satu kebaikan untuk kebaikan yang lain. ${ }^{11}$ Manusia abai kepada Allah bila tidak bersuci, abai bila telah bersuci tapi tidak salat, abai bila setelah salat tidak berdoa. Allah bukan pengabai, sehingga mustahil bagi-Nya bila tidak mengabulkan permohonan hamba-Nya. Manusia tidak perlu menyibukkan diri dengan selain beribadah kepada Allah. Karena gudang rezeki hanya milik-Nya. Orang yang tidak pernah melupakan Allah akan memperoleh kenikmatan sejati yakni kehadiran Allah dan Dia membuka segala hijab.

\footnotetext{
${ }^{11}$ Setiap kebaikan harus disusul kebaikan lainnya. Karena setiap keburukan akan menyusulkan keburukan lainnya. Lihat, Khalid A. Mu'thi Khalif, Nasihat untuk Orang-orang Lalai (Jakarta: Gema Insani Press, 2005), 87.
}

Manusia tidak perlu takut kepada para penguasa, karena kekuasaan sejati hanya ada pada-Nya. Sementara itu kekuasaan Allah tidak akan pernah lenyap. Tidak perlu manusia merasa resah kecuali keresahan bila kehilangan pertolongan Allah. Dan manusia tidak boleh merasa aman dari siasat Allah kecuali dia telah melewati titi șirāt mustaqìm. Bila telah menjadi penghuni surga, maka mendapatkan kenikmatan melihat keindahan Allah. Semua itu adalah berkat kebesaran-Nya. Itu untuk yang salat dengan rendah hati, tidak larut dengan maksiat, menjeda kesibukan siang dengan zikir, mengasihani orang miskin, membantu musafir, memudahkan orang kesulitan, mengasihi yang musibah. Orang demikian adalah seperti cahaya, Allah melindinginya, mengirim malaikat untuk menjaganya, meneranginya dalam gelap, diberi Allah kepadanya ilmu. Bagaimana Allah mencintai orang berilmu? Bila dia berniat melakukan keburukan lalu membatalkan niatnya tersebut, baginya satu kebaikanya karena dia mengurungkan niatnya itu semata karena Allah.

Allah Maha Mulia dan Maha Luhur pada sepertiga malam berseru bahwa Dia adalah Raja. Maka siapa berdoa maka dikabulkan, siapa memohon maka dianugerahi dan siapa meminta ampun maka diampuni. Allah akan 
TUHAN MENURUT TUHAN: Narasi Ilahiyah dalam Hadis Qudsī

menyempurnakan ibadah-ibadah wajib hamba-Nya yang tidak sempurna dengan ibadah-ibadah sunatnya. Demikianlah Keluhuran-Nya.

Manusia harus senantiasa sadar bahwa kemiskinan, penyakit dan kematian adalah ketentuan mutlak Allah. Tugas manusia adalah tidak mengeluhkannya, senantiasa patuh, jangan pusing dengan rezeki, jangan pernah merasa telah aman, jangan merasa dosa telah diampuni dan jangan pernah lengah dari tipu daya. Hendaklah pula manusia tidak mengejar jabatan karena di sana ada kesibukan duniawi yang menunggu. Jangan pula menentang para kekasih Allah kerena itu berarti deklarasi perang dengan Allah.

Allah menyeru manusia agar terusmenerus meminta kepada-Nya, jangan pernah mengeluhkan waktu karena Dia-lah Sang Waktu. Dengan begitu Allah selalu memberinya karunia dan mengampuni dosa-dosanya.

Bagi yang keluar berjihad semata hanya karena Allah maka dia akan kembali dengan pahala dan rampasan perang. Surga adalah balasan terbaik bagi mujahid. Mereka sangat nyaman di dalamnya. Ketika mereka ditanya keinginan di dalam surga, mereka ingin kembali ke bumi untuk terbunuh syahid lagi, lalu hidup kembali dan syahid lagi, demikian seterusnya. Nabi Muhammad sendiri ingin seperti itu. ${ }^{12}$

Kemuliaan juga diberikan kepada orang-orang dalam majelis zikir. Mereka memuji, mengagungkan dan menyucikan Nama Allah. Allah menjanjikan surga, perlindungan dan menghindarkan mereka dari surga. Bahkan orang yang tidak ikut berzikir bersama majelis, tetapi datang untuk maksud lain, tetap saja mendapatkan kemuliaan dari Allah. Orang yang menyucikan Allah, dengan kalimat tauhid, maka baginya timbangan yang lebih berat daripada tujuh bumi dan segala isinya.

Demikian juga Allah memberikan keselamatan dan kesejahteraan sepuluh kali setiap mengucapkan salawat kepada Nabi Muhammad. Rahmat Allah juga dilimpahkan kepada orang-orang yang menyambung silaturrahmi. $^{13}$ Allah mewajibkan kasih sayang-Nya bagi siapa yang saling mengasihi, saling menolong dan saling mengunjungi semata karena Allah. Sebaliknya siapa yang memutus hubungan silaturrahmi, maka akan dilaknat Allah. Dan Nabi Muhammad mengaminkan yang demikian. Allah mengatakan DiriNyalah yang sakit, Diri-Nyalah yang meminta makan dan minum melalui orang

\footnotetext{
${ }^{12}$ Keutamaan Jihad, lihat, Aidh Al-Qarni, Cahaya Zaman (Jakarta: Gema Insani Press, 2006), 102.

${ }^{13}$ Abdul Azizi ibn Fauzan ibn Shalih, Fikih Sosial: Tuntunan dan Etika Hidup Bermasyarakat (Jakarta: Qisthi Press, 2016), 267.
} 
yang sakit, kekurangan makanan dan kekurangan minuman. Karena bila mengunjungi orang sakit, memberi makan dan minum bagi yang membutuhkan maka akan menemukan Allah di sisinya.

Bila Allah menyintai seseorang, maka Dia menyeru kepada Jibril dan seluruh isi langit untuk mencintai dia. Lalu Allah membuatnya disukai di bumi. Sebaliknya bila Allah tidak menyukai seseorang, maka ia menyeru kepada Jibril dan seluruh isi langit untuk tidak menyukai dia. Lalu Allah membuatnya tidak disukai di bumi.

Perkara yang tidak disukai Allah adalah karena berbuat dosa. Tetapi bila seseorang berbuat dosa lalu memohon ampunan Allah, maka Dia mengatakan bahwa hamba-Nya tahu bahwa dia mempunyai Tuhan yang mengampuni dosa dan menghukum perbuatan dosa. Maka Allah mengampuninya. Allah tidak peduli keburukan yang dilakukan asalkan dia mau bertaubat dan tidak mengulangi perbuatan itu. Allah juga tidak peduli perbuatanperbuatan baik kecuali yang semata-mata dilakukan demi dambaan Wajah-Nya.

Orang yang hanya sibuk melayani Allah akan dilayani oleh dunia. Sementara yang sibuk melayani dunia, maka dunia akan membuatnya sibuk dan lelah. Siapa saja yang telah diberikan keluasan hidup oleh Allah sementara dia tidak berpaling
kepada-Nya, maka ia tertolak. Segala amal dicatat para malaikat. Tetapi hatinya hanya Allah yang tahu. Karena itu, orang yang beramal dapat dikutuk oleh Allah bila dia melakukannya bukan karena Allah.

Orang hafal Alquran dengan harapan dikenal sebagai hăfiz, orang kaya berdermal agar dikenal sebagai dermawan, orang mati dalam perang agar dikenal sebagai pemberani akan dipakai untuk mengibarkan api neraka. Allah sangat membenci orang yang melupakan Diri-Nya, dengan berbuat dengan orientasi selain Dia, mereka melakukan kemunafikan.

Sementara ada tiga golongan yang doanya tidak akan ditolak Allah karena mereka tulus. Pertama adalah yang berpuasa hingga dia berbuka, kedua adalah imam yang adil dan ketiga orang yang dizalimi. Mereka adalah orang-orang yang sadar bahwa dunia adalah tempat berusaha, hasilnya itu di akhirat. Di surga, manusia diberikan sesejahteraan, kekekalan, dipenuhi segala keinginan, diberi kebun yang indah, pasangan yang disukai dan makanan berlimpah. Dan kenikmatan diatas segalanya adalah memandang Wajah Allah.

\section{Kesimpulan}

Ternyata Tuhan dalam hadis $q u d s \bar{\imath}$ tidak tampil sebagai sosok pemarah, pendendam, pengazab. Dia hadir sebagai pemaaf yang senantiasa menunggu hamba- 
TUHAN MENURUT TUHAN: Narasi Ilahiyah dalam Hadis Qudsī

Nya untuk datang bertaubat. Dia tidak model keyakinan tertentu, sementafa fukaha peduli sebesar apapun dosa hamba-Nya. melihat Tuhan sebagai sosok yang siap Karena ampunan-Nya lebih besar dari menyiksa siapa saja yang membangkang sebesar dan sebanyak apapun dosa yang sanggup dilakukan manusia. Ini sangat penting karena bila mencitrakan bahwa ada dosa-dosa tertentu yang tidak diampuni Tuhan, maka akan membuat orang menjadi pesimis. Sikap pesimis inilah yang membuat Iblis enggan bertaubat kepada Allah. Padahal enggan bersujud pada Adam dapat saja dimaafkan.

'Urafā' menjadi berbeda dengan mutakallimīn dan fukaha karena mereka tidak melihat Tuhan sebagai pengazab dan pemarah. 'Urafā' melihat Tuhan sebagai pecinta yang senantiasa menanti kehadiran hamba sebagai kekasihnya. Bila dalam teologi Tuhan dilihat sebagai sosok agung yang membenci segala keyakinan kecuali kepada-Nya, sementara dalam irfān, Tuhan dipandang sebagai kekasih yang selalu melimpahkan kasih sayang kepada hambaNya.

Kelangkaan citra negatif bagi Tuhan dalam pandangan 'irfān itulah yang membuat 'urafā' gemar menggunakan hadis qudsī sebagai pengayaan referensi mereka. Karena pandangan mistik yang mereka temukan dalam perjalanan spiritual, sesuai dengan pesan-pesan Tuhan dalam hadis qudsī. Untuk itu, sudah selayaknya hadis qudsī mendapatkan tempat yang lebih proporsional dalam memperkenalkan agama, agar tidak terkesan sebagai sebuah ajaran yang kaku dan kering.

\section{DAFTAR PUSTAKA}

Al-Qarni, Aidh. Cahaya Zaman. Jakarta: Gema Insani Press, 2006.

Ibn Arabi. 'Relung Cahaya: Seratus Satu Hadis Ketuhanan. Jakarta: Pustaka Firdaus, 1998.

Iqbal, Muhammad. Rekonstruksi Pemikiran Religius dalam Islam. Bandung: Mizan, 2001.

Isa, Abdul Qadir. Hakekat Tasawuf. Jakarta: Qisthi Press, 2005.

Jaelani, Abdul Qadir. Bekal yang Cukup Menuju Allah Azza Wajalla. Jakarta: Sahara, 2009.

Jazuli, Ahzami Samiun. Kehidupan dalam Pandangan Alquran. Jakarta: Gema Inani Press, 2006.

Khalid, A. Mu'thi Khalif. Nasihat untuk Orang-Orang Lalai. Jakarta: Gema Insani Press, 2005. 
Motinggon, Quitor. Keajaiban Cinta: Membuat Hidup Lebih Berenergi dan Dinamis. Jakarta: Hikmah, 2005.

Rafiqi, Yusep. Belajar Hidup dari Allah. Jakarta: Gramedia, 2015.

Ibn Shalih, Abdul Azizi ibn Fauzan. Fikih Sosial; Tuntunan dan Etika Hidup Bermasyarakat. Jakarta: Qisthi Press, 2016.

Sunarto, Achmad \& Syamsuddin Noor. Himpunan Hadis Qudsī. Jakarta: An-Nur, 2005.

Yunardi, S \& Muhammad. Kekuatan Memaafkan. Jakarta: Qibla, 2014. 
TUHAN MENURUT TUHAN: Narasi Ilahiyah dalam Hadis Qudsī 